DOI: https://doi.org/10.47405/mjssh.v5i1.412

\begin{tabular}{|c|c|}
\hline 1. 1.54 & Malaysian Journal of Social Sciences and Humanities (MJSSH) \\
\hline $\begin{array}{c}\text { Malaysian Journal of } \\
\text { solal sciences and }\end{array}$ & Volume 5, Issue 1, January 2020 \\
\hline (MJ-SSH) & e-ISSN : 2504-8562 \\
\hline & $\begin{array}{l}\text { Journal home page: } \\
\text { www.msocialsciences.com }\end{array}$ \\
\hline
\end{tabular}

\title{
Perspektif Terhadap Mata Pelajaran Sejarah Melalui Pembelajaran Berasaskan Dokumen
}

\author{
M. Kaviza1 \\ 1Pusat Pengajian Pendidikan dan Bahasa Moden, Universiti Utara Malaysia (UUM) \\ Correspondence: M. Kaviza (kavizakaviza@yahoo.com)
}

\begin{abstract}
Abstrak
Kajian tinjauan secara deskriptif ini bertujuan untuk mengenal pasti tahap perspektif murid terhadap mata pelajaran sejarah dari aspek sebagai proses analisis, sebagai proses kefahaman dan sebagai proses imaginasi melalui pembelajaran berasaskan dokumen. Seramai 55 orang murid tingkatan empat yang ditentukan berdasarkan teknik persampelan bertujuan terlibat dalam kajian ini. Instrumen kajian ini merupakan soal selidik yang telah disemak kesahannya oleh pakar penilai dan mempunyai nilai kebolehpercayaan yang baik. Data kajian ini dianalisis secara deskriptif melalui perisian IBM SPSS. Dapatan kajian ini menunjukkan bahawa tahap perspektif murid terhadap mata pelajaran sejarah secara keseluruhannya berada pada tahap tinggi. Tambahan pula, perspektif murid terhadap mata pelajaran sebagai proses analisis, sebagai proses kefahaman dan sebagai proses imaginasi berada pada tahap tinggi. Implikasi kajian ini telah memaparkan sumber maklumat bahawa pembelajaran berasaskan dokumen dapat membentuk perspektif murid yang baik terhadap mata pelajaran sejarah.
\end{abstract}

Kata kunci: mata pelajaran sejarah, perspektif, pembelajaran berasaskan dokumen

\section{Perspective on History Subject via Document-Based Learning}

\begin{abstract}
This descriptive survey study aims to identify the level of students' perspective on history subject in terms as analytical, understanding and imaginative process via document-based learning. A total of 55 form four students which are selected through purposive sampling technique involved in this study. The instrument of this study is a questionnaire which has been validated by the expert and has a good reliability values. The data of this study were analyzed descriptively using IBM SPSS software. The findings of this study indicated that the students perspective on history subject at the high level. In addition, the level of students' perspective on history as analytical, understanding and imaginative process at high level in this study. The implications of this study proved that document-based learning can develop a positive perspective on history subject.
\end{abstract}

Keywords: history subject, perspective, document-based learning 


\section{Pengenalan}

Sejarah merupakan mata pelajaran teras dalam kurikulum sejarah yang wajib dipelajari oleh semua murid secara berterusan dari Tingkatan Satu hingga Tingkatan Lima dengan memfokuskan kepada elemen kandungan, kemahiran dan nilai (Pusat Perkembangan Kurikulum [PPK], 2018). Sehubungan dengan itu, pihak PPK (2018) telah menyenaraikan objektif kurikulum sejarah sekolah menengah yang perlu dicapai dalam kalangan murid seperti menyatakan kepentingan sejarah dalam kehidupan seharian dengan mengambil iktibar daripada peritiwa sejarah, menerangkan kepentingan mengamalkan semangat perpaduan dalam usaha pembangunan dan kemajuan negara, mengaplikasikan kemahiran pemikiran sejaran dalam kalangan murid melalui proses pengajaran dan pembelajaran sejarah dalam memahami peristiwa sejarah, menjelaskan pencapaian kemajuan negara dalam melahirkan murid untuk bersaing di peringkat global, menghuraikan usaha dan sumbangan tokoh tanah air dalam memperjuang dan mempertahankan kedaulatan negara, menghuraikan perkembangan sejarah masyarakat dan negara bagi membina jati diri, menilai kepentingan dan peranan, kepelbagaian kaum serta etnik dalam pembentukan negara bangsa, mengaplikasikan dan meningkatkan kemahiran berfikir aras tinggi melalui fakta-fakta sejarah yang tepat, membina minat terhadap sejarah sebagai satu disiplin ilmu yang dinamik dan akhir sekali membina semangat patriotik dalam mempertahankan kedaulatan negara.

Sungguhpun begitu, terdapat perspektif murid-murid yang telah melabelkan proses pembelajaran mata pelajaran sejarah sebagai suatu yang membosankan, tidak menarik, terlalu formal, tidak fleksibel, tiada kreativiti, dan tidak mencabar minda (Abdul Razaq \& Andi Suwirta, 2007; Rosy Talin, 2014; Mohamad Johdi Salleh, Baharom Mohamad \& Abdul Said Ambotang, 2013; Sharifah Nor Puteh, Nooreiny Maarof \& Elisabeth Tak, 2010; Azwan Ahmad, Abdul Ghani Abdullah, Mohamad Zohir Ahmad \& Abdul Rahman Haji Abdul Aziz, 2005; Chee-Huay \& Kee-Jian, 2016). Perspektif-perspektif murid sebegini sudah tentu akan menggagalkan pencapaian objektif kurikulum yang disarankan oleh pihak PPK serta menjadi faktor penghalang kepada pembentukan masyarakat yang berdaya saing pada masa hadapan seperti yang dihasratkan dalam dasar pendidikan negara melalui Pelan Pembangunan Pendidikan Malaysia (Kementerian Pendidikan Malaysi [KPM], 2013). Adalah tidak dapat disangkal bahawa perspektif-perspektif negatif terhadap mata pelajaran sejarah yang diutarakan tersebut wujud akibat daripada pelaksanaan gaya pengajaran yang berpusatkan guru (Anuar Ahmad, Siti Haishah Abdul Rahman \& Nur Atiqah T Abdullah, 2009; Mohd Samsudin \& Shahizan Shaharuddin, 2012) yang telah mencadangkan kepada pelaksanaan strategi pengajaran dan pembelajaran yang dapat menarik minat dan mengubah perspektif murid terhadap taraf, status dan identiti mata pelajaran sejarah tersebut.

Rentetan daripada itu, proses pengajaran dan pembelajaran sejarah perlulah memfokuskan kepada pembinaan kefahaman dan pengetahuan, menyediakan peluang untuk tujuan penjelasan sejarah dilakukan, berkebolehan dalam membuat penyiasatan sejarah dengan menggunakan pelbagai jenis sumber yang berbeza, kemampuan membuat tafsiran perkara yang telah lepas berdasarkan bukti, berkeupayaan untuk memilih dan menyusun maklumat, mampu mengemukakan dapatan dengan tepat, membentuk kesedaran tentang bagaimana peristiwa masa lalu memperihalkan peristiwa masa kini dan mempertimbangkan idea-idea sejarah secara rasional (PPK, 2003, 2018; Mohamad Johdi Salleh, Baharom Mohamad \& Abdul Said Ambotang, 2013; Bruno-Jofre, 2010; Slekar, 2009; Morais, 2018). Justeru, pembelajaran berasaskan dokumen diharapkan dapat memenuhi hasrat kurikulum sejarah tersebut. Hal ini kerana pembelajaran berasaskan dokumen merupakan proses pembelajaran yang berteraskan kepada aspek pengkajian bahan-bahan dan sumber-sumber yang berbentuk teks (Stovel, 2000; Theresa \& Nonen, 1999; Sandwell, 2008; Van Hover, Hick \& Dack, 2016; Ayu, 2016) dan diakui manfaatnya dalam pendidikan sejarah iaitu dalam mewujudkan proses pembelajaran secara mendalam, peningkatan kemahiran berfiki, menjana sifat ingin tahu yang baik dan menggalakkan murid-murid menjadi lebih aktif, kritikal, kreatif dan inovatif (Culminas-Clis \& Reyers, 2016; Nusbaum, 2014; Woyshner, 2010; Reisman, 2012; Nokes, 2014). Namun, tahap perspektif muridmurid terhadap mata pelajaran melalui pembelajaran berasaskan dokumen perlu diketahui bagi menyediakan sumber maklumat kepada para guru dalam membuat perancangan dan pelaksanaan strategi pembelajaran tersebut dengan baik di dalam kelas. Maka, kajian ini bertujuan untuk mengenal pasti tahap persepstif murid terhadap mata pelajaran sejarah melalui pembelajaran berasaskan dokumen. 


\section{Objektif Kajian}

Objektif kajian ini adalah seperti berikut:

Mengenal pasti tahap perspektif terhadap mata pelajaran sejarah dari aspek:

i. Mata pelajaran sejarah sebagai proses analisis

ii. Mata pelajaran sejarah sebagai proses kefahaman

iii. Mata pelajaran sejarah sebagai proses imaginasi

\section{Soalan Kajian}

Soalan kajian ini adalah seperti berikut:

Apakah tahap perspektif terhadap mata pelajaran sejarah?

i. Apakah tahap perspektif terhadap mata pelajaran sejarah sebagai proses analisis?

ii. Apakah tahap perspektif terhadap mata pelajaran sejarah sebagai proses kefahaman?

iii. Apakah tahap perspektif terhadap mata pelajaran sejarah sebagai proses imaginasi?

\section{Metod Kajian}

Kajian tinjauan berbentuk deskriptif (Creswell, 2014) ini melibatkan 55 orang murid Tingkatan Empat yang dipilih melalui teknik persampelan bertujuan dari sebuah sekolah menengah harian di utara Semenanjung Malaysia. Instrumen kajian ini merupakan soal selidik yang dibina oleh pengkaji berdasarkan tinjauan literatur kajian-kajian lepas. Instrumen tersebut telah disahkan oleh dua orang pakar penilai dalam bidang pengajaran sejarah yang berpengalaman dan mempunyai nilai kebolehpercayaan Cronbach Alpha iaitu 0.90 yang dianggap baik dan boleh diterima untuk tujuan kajian ini (Nunnally, 1978). Data kajian ini telah dianalisis secara deskriptif iaitu min dan sisihan piawai melalui perisian IBM SPSS. Interpretasi tahap persepsi murid dalam kajian ini dilakukan berdasarkan tiga tahap skor min yang diadaptasi daripada kajian Jamil Ahmad, (2002) seperti ditunjukkan pada Jadual 1.

Jadual 1: Interpretasi Skor Min dan Tahap Perspektif Murid

\begin{tabular}{cc}
\hline Skor Min & Tahap \\
\hline $1.00-2.33$ & Rendah \\
$2.34-3.66$ & Sederhana \\
$3.67-5.00$ & Tinggi \\
\hline
\end{tabular}

Sumber: Adaptasi daripada Jamil Ahmad, (2002)

\section{Dapatan Dan Perbincangan Kajian}

\section{Tahap perspektif terhadap mata pelajaran sejarah}

Berdasarkan Jadual 2, tahap perspektif terhadap mata pelajaran sejarah berada pada tahap tinggi $(M=3.83, S D=0.78)$. Justeru, dapat dirumuskan bahawa tahap perspektif murid terhadap mata pelajaran sejarah secara keseluruhannya melalui pembelajaran berasaskan dokumen adalah tinggi dalam kajian ini. Dapatan kajian ini adalah selari dengan dapatan kajian Khairul Ghufran Kaspin, Mansor Mohd Noor dan Mohd Mahzan Awang (2018) yang melaporkan bahawa perspektif murid terhadap kurikulum sejarah peringkat menengah di Malaysia berada pada tahap baik, di samping dapatan kajian Mansor Mohd Noor dan Khairul Ghufran Kaspin, (2015) yang turut melaporkan bahawa tahap keberkesanan mata pelajaran sejarah dalam membina etos bangsa generasi muda di Malaysia adalah baik. Sungguhpun begitu, tahap perspektif murid terhadap mata pelajaran sejarah selepas mengikuti 
pembelajaran berasaskan dokumen dalam kajian ini adalah konsisten dengan dapatan kajian Rohaimi Ishak dan Ramlah Jantan (2015) yang menunjukkan bahawa tahap persepsi terhadap perubahan sikap murid selepas mempelajari sejarah adalah tinggi dan kajian Mohamad Johdi Salleh dan Ariegusrini Agus (2011) serta kajian Anandan \& Sumathi (2017) yang melaporkan bahawa minat, motivasi dan pencapaian murid adalah dipengaruhi oleh pengajaran sejarah yang telah menyokong dapatan kajian ini secara tidak langsung. Hal ini kerana pembelajaran berasaskan dokumen dapat mengubah peranan, tanggapan dan pendirian seseorang murid terhadap mata pelajaran sejarah ke arah yang lebih baik dan positif disebabkan oleh murid-murid merasakan proses pembelajaran sejarah tersebut adalah tidak membosankan dan dapat menarik minat mereka untuk belajar dengan lebih bersungguh-sungguh (Nokes, 2014; Fogo, Reisman \& Breakstone, 2019; Logtenberg, Van Boxtel \& Hout-Wolters, 2011).

Jadual 2: Min dan tahap Perspektif terhadap Mata Pelajaran Sejarah

\begin{tabular}{lccc}
\hline & Min & $\begin{array}{c}\text { Sisihan } \\
\text { Piawai }\end{array}$ & Tahap \\
\hline Perspektif terhadap mata pelajaran sejarah & 3.83 & 0.78 & Tinggi \\
\hline
\end{tabular}

\section{Tahap perspektif terhadap mata pelajaran sejarah sebagai proses analisis}

Berdasarkan Jadual 3, tahap perspektif terhadap mata pelajaran sejarah sebagai proses analisis berada pada tahap tinggi $(M=4.01, S D=0.77)$. Justeru, dapat dirumuskan bahawa tahap perspektif murid terhadap mata pelajaran sejarah sebagai proses analisis melalui pembelajaran berasaskan dokumen adalah tinggi dalam kajian ini. Tahap yang tinggi bagi perspektif terhadap mata pelajaran sebagai sebagai proses analisis yang dilaporkan dalam kajian ini adalah sealiran dengan dapatan kajian Reisman (2012), kajian Woyshner (2010), kajian Swams, Hofer dan Gallichio (2006) yang menjelaskan bahawa penggunaan sumber-sumber sejarah dapat menggalakkan proses penyiasatan mendalam dalam mencari kebenaran dan kesignifikan sesuatu peristiwa sejarah yang telah berlaku. Oleh kerana, pembelajaran berasaskan dokumen melibatkan aktiviti menganalisis dan meneroka kandungan sejarah secara hands-on dan minds-on telah menjadi pilihan kepada murid untuk mengikuti proses pembelajaran tersebut dengan baik. Pilihan dan keperluan murid untuk melibatkan diri dalam aktiviti pembelajaran sejarah yang lebih mencabar minda mereka, menjana pemikiran kritis, menarik dan penguasaan kandungan sejarah secara mendalam turut diutarakan oleh Rosfiani, Akhbar dan Neolaka, (2019), Rosy Talin (2013), Van Hover, Hicks dan Dack, (2016), Cosme, Carrasco dan Martinez, (2016), Boadu, (2015), Barton \& Linda (2004) dan Lezah@Lejah Kiamsen dan Rosy Talin, (2018) yang melaporkan bahawa murid-murid sejarah lebih gemar untuk mengikuti kaedah pengajaran seperti kaedah perbincangan, soal jawab, gallery walk, perbahasan, kaedah inkuiri dan sebagainya yang berpaksikan kepada pendekatan pembelajaran berpusatkan murid.

Jadual 3: Min dan tahap Perspektif terhadap Mata Pelajaran Sejarah sebagai Proses Analisis

\begin{tabular}{lccc}
\hline & Min & $\begin{array}{c}\text { Sisihan } \\
\text { Piawai }\end{array}$ & Tahap \\
\hline Proses analisis & 4.01 & 0.77 & Tinggi \\
\hline
\end{tabular}

\section{Tahap perspektif terhadap mata pelajaran sejarah sebagai proses kefahaman}

Berdasarkan Jadual 4, tahap perspektif terhadap mata pelajaran sejarah sebagai proses kefahaman berada pada tahap tinggi $(M=3.78, S D=0.72)$. Justeru, dapat dirumuskan bahawa tahap perspektif murid terhadap mata pelajaran sejarah sebagai proses kefahaman melalui pembelajaran berasaskan dokumen adalah tinggi dalam kajian ini. Tahap perspektif murid terhadap mata pelajaran sebagai proses kefahaman yang tinggi dalam kajian ini adalah bertepatan dengan pendapat Stearns (1998), Berg (2019), Wineburg, Smith dan Breakstone, (2018), Tan, (2004) dan Joseph (2011) yang telah menjelaskan walaupun mata pelajaran sejarah kaya dengan pelbagai fakta dan maklumat penting dan padat, namun ianya bukanlah sesuatu yang melibatkan proses penghafalan semata-mata, malah fakta dan maklumat tersebut perlu difahami maknanya dengan mendalam. Perkara yang sama juga telah 
DOI: https://doi.org/10.47405/mjssh.v5i1.412

disarankan dalam kurikulum sejarah iaitu matlamat utama kurikulum sejarah adalah memberi kefahaman mendalam kepada murid mengenai masyarakat, negara Malaysia dan dunia (PPK, 2018). Rentetan daripada itu, pengkaji Baildon, Rajah dan Afendi (2019) juga turut menjelaskan bahawa perspektif murid terhadap mata pelajaran sejarah sebagai proses kefahaman terbentuk apabila minat untuk belajar sejarah dapat dirangsangkan dengan baik melalui joyful relationship, sense of belonging, autonomy, experiential learning, authentic intellectual work dan meaningful assessment. Tambahan pula, tahap perpektif terhadap proses kefahaman yang tinggi melalui pembelajaran berasaskan dokumen adalah disebabkan oleh murid-murid dapat memahami peristiwa masa lalu dan mengetahui kepentingan peristiwa tersebut melalui proses tafsiran dan interpretasi sumber (Allen, 2011; Stewart, Iran-Nejad \& Robinson, 2008; Nersater, 2019; Thorp \& Persson, 2020; Brooks, 2013).

Jadual 4: Min dan tahap Perspektif terhadap Mata Pelajaran Sejarah sebagai Proses Kefahaman

\begin{tabular}{lccc}
\hline & Min & $\begin{array}{c}\text { Sisihan } \\
\text { Piawai }\end{array}$ & Tahap \\
\hline Proses kefahaman & 3.78 & 0.72 & Sederhana \\
\hline
\end{tabular}

\section{Tahap perspektif terhadap mata pelajaran sejarah sebagai proses imaginasi}

Berdasarkan Jadual 5, tahap perspektif terhadap mata pelajaran sejarah sebagai proses imaginasi berada pada tahap tinggi $(M=3.84, S D=0.85)$. Justeru, dapat dirumuskan bahawa tahap perspektif murid terhadap mata pelajaran sejarah sebagai proses imaginasi melalui pembelajaran berasaskan dokumen adalah tinggi dalam kajian ini. Tahap perspektif yang tinggi yang dilaporkan dalam kajian ini adalah seiring dengan teras struktur disiplin sejarah yang dinyatakan dalam kurikulum sejarah iaitu kefahaman sejarah yang baik dapat dijana apabila murid-murid dapat memahami kehidupan manusia zaman silam apabila mereka digalakkan melihat zaman tersebut secara empati dan imaginatif (PPK, 2003; 2018). Penjelasan ini adalah bertepatan dengan pendapat Lemisko (2004) dan Hart (1910) yang memperincikan bahawa sejarah itu merupakan gambaran masa lepas yang mempunyai kesignifikan dan kesahannya terhadap pemahaman dan penguasaan pengetahuan. Hal ini kerana melalui proses analisis kandungan dokumen dalam mata pelajaran sejarah, murid-murid mampu untuk berfikir untuk memerihalkan sesuatu perkara dan peristiwa secara konkrit dan autentik dari pelbagai kaca mata pengkajian, di samping membuat tanggapan dan membayangkan sesuatu idea,, konsep, keadaan atau gagasan terhadap perkara-perkara dalam minda secara visual dan empati (perasaan), serta mengembangkan daya kreativiti dalam melakarkan peta minda atau bentuk lain terhadap sesuatu peristiwa sejarah (Siti Hawa Abdullah \& Aini Hassan, 2007; Colby, 2008; Lenn, Boxtel \& Wilschot, 2019; Dorothy, 1984; Ramaroka \& Engelbrech, 2018; Atkins, 2019; Perrota, 2018; Dunn \& Wyner, 2019).

Jadual 5: Min dan tahap Perspektif terhadap Mata Pelajaran Sejarah sebagai Proses Imaginasi

\begin{tabular}{lccc} 
& Min & $\begin{array}{c}\text { Sisihan } \\
\text { Piawai }\end{array}$ & Tahap \\
\hline Proses imaginasi & 3.84 & 0.85 & Tinggi \\
\hline
\end{tabular}

\section{Kesimpulan}

Kesimpulannya, tahap perspektif murid terhadap mata pelajaran sejarah melalui pembelajaran berasaskan dokumen berada pada tahap tinggi dalam kajian ini. Dapatan kajian ini diharapkan dapat dijadikan panduan kepada para guru untuk memantapkan lagi pelaksanaan kaedah pedagogi sejarah yang dapat mengubah perspektif positif murid terhadap mata pelajaran sejarah selaras dengan pencapaian objektif kurikulum sejarah iaitu untuk membina minat terhadap sejarah sebagai satu disiplin ilmu yang dinamik. 


\section{Rujukan}

Abdul Razaq Ahmad \& Andi Suwirta. 2007. Sejarah dan pendidikan Sejarah: Perspektif Malaysia dan Indonesia. Bandung: Historia Utama Press.

Allens, R.B. (2011). Developing a knowledge based to improve interaction with collections of historical newspaper. International Ferderation of Library Association: San Juan.

Anandan, K \& Sumathi, R. (2017). A study on attitude towards history and achievement in history among X students' in Thirullaur District. International Educational Scientific Research Journal, $3(7), 56-61$.

Anuar Ahmad, Siti Haizhah Abdul Rahman \& Nur Atiqah T Abdullah. (2009). Tahap pengajaran guru sejarah dan hubungannya dengan pencapaian murid di sekolah berprestasi rendah. Jurnal Pendidikan Malaysia, 34(1), 53-66.

Atkins, K. (2019). Historical imagination skills of preschool children as reflected in their clay works. International Online Journal of Educational Sciences, 11(3), 87-104.

Ayu, M. (2016). Documents as learning materials for local history study course Batik Janegaroon for students majoring in the History of the state University of Malay. Proccedings International Conference: Ultilization of Historical Sources in learning, 8 Oktober 2016, Aula Fakultas Ilmu Sosial: Universitas Negeri Malang.

Azwan Ahmad, Abdul Ghani Abdullah, Mohamad Zohir Ahmad \& Abdul Rahman haji Abdul Aziz (2005). Kesan efikasi kendiri guru sejarah terhadap amalan pengajaran berbantukan teknologi maklumat dan komunikasi (ICT). Jurnal Penyelidikan Pendidikan, 7, 15-24.

Baildon, M., Rajah, C \& Afandi, S. (2019). Sparking Joy in History Classrooms. HSSE Online, 8(1), 66-76.

Barton, K.C \& Linda, S.L. (2004). Teaching history for the common good. Mahwah: Erlbaum Associates.

Berg, C.W. (2019). Why study history? An examination of undergraduate students native and perceptions about history. The encounters: A Journal of Historical Consciousness, Historical cultures and Historical Education, 6(1), 54-71.

Boadu, G. (2015). Effective teaching in history: The perspectives of history students-teachers. International Journal of Humanities and Social Sciences, 3(1), 38-51.

Brooks, S. (2013). Teaching for historical understanding in the advanced placement program: A case study. The History Teacher, 47(1), 61-76.

Bruno-Jofre, R. (2010). Teaching history. Education Letter, 1-3.

Chee-Huay, C \& Kee-Jian, Y. (2016). Why students fail in history: A minor case study in Malaysia and solutions from cognitive psychology perspectives. Mediterranean Journal of Social Sciences, $7(1), 517-526$.

Colby, S.R. (2008). Energizing the history classroom: Historical narratives inquiry and historical empathy. Social Studies Research and Practice, 3(3), 60-79.

Cosme, J., Carrasco, G \& Martinez, P.W. (2016). Historical skills in compulsory education: Assessment, inquiry based strategies and students argumentation. New Approaches in Educational Research, 5(2), 130-136.

Creswell, J. W. (2014). Educational Research: Planning, Conducting and Evaluating Quantitative and Qualitative Research ( $4^{\text {th }}$ Ed). New Jersey: Pearson Prentice Hall.

Culminas-Colis, M.V \& Reyers, W.M. (2016). Teaching historical thinking skills through "reading Like A Historian" Method. The Normal Light, 10(1), 1-22.

Dorothy, B.S. (1984). 'Hard' "Facts and facts" sources: Literature as Historical source material? Nordic association for American Studies, 16(2), 74-80.

Dunn, R \& Wyner, S. (2019). Before 'us' and 'now': developing a sense of historical consciousness and identity of the museum. International Journal of Early Years education, 1-14.

Fogo, B., Reisman, A \& Breakstone, J. (2019). Teacher adaptation of document-based history curricula: results of the reading like a historian curriculum-use survey. Journal of Curriculum Studies, 1-22.

Hart, A.B. (1910). Imagination in history. The American Historical Review, 15 (2), 227-251.

Joseph, S. (2011). What are upper secondary school students saying about history? Carribbean Curriculum, 18, 1-26. 
Khairul Ghufran Kaspin, Mansor Mohd Noor \& Mohd Mahzan Awang. (2018). Perspektif pelajar terhadap kurikulum sejarah peringkat menengah di Malaysia. Jurnal Pemikir Pendidikan, 9, $12-$ 31.

Lemisko, L.S. (2004). The historical imagination: Collingwood in the classroom. Canadian Social Studies, 38(2), 1-9.

Lenn, T.D, Boxtel, C.V \& Wilshut, A. (2019). 'When I'm drawing, I see picture in my head': Secondary schools students constructing an image of the past by mean of a drawing tasks and writing task. European Journal of Psychology of Education, 1-21.

Lezah@Lejah Kiamsen \& Rosy Talin. (2018). Kaedah pengajaran sejarah yang diminati pelajar dan justifikasinya. Malaysian Journal of Social Sciences and Humanities, 3(2), 137-145.

Logtenberg, A., Van Boxtel \& Hout-Wolters, B. (2011). Stimulating situational interest and student optimizing through three types of historical introductory text. European Journal of Psychology of Education, 26(2), 179-198.

Mansor Mohd Noor \& Khairul Ghufran Kaspin. (2015). Keberkesanan mata pelajaran sejarah dalam membina etos bangsa generasi muda di Malaysia. Jurnal Komunikasi Borneo Edisi Khas, 29-46.

Mohamad Johdi Salleh, Baharom Mohamad \& Abdul Said Ambotang. (2013). The significant of history curriculum in the development of active citizen: A critical analyses of the ICSS History, Malaysia. International Journal of Scientific and Research Publication, 3(9), 1-8.

Mohamad Johdi Salleh \& Ariegusrini Agus (2011). An analysis of multi-ethnics students' attitudes in the teaching and learning history at the selected secondary schools in Sabah Malaysia. HISTORIA: International Journal of History Education, 7(2), 240-254.

Mohd Samsudin \& Shahizan Shaharuddin. (2012). Pendidikan dan pengajaran mata pelajaran sejarah di sekolah di Malaysia. Jebat: Malaysian Journal of History, Polities \& Strategy, 39(2), 116-141.

Morais, D.G. (2018). Doing history in the undergraduate classroom: Project based learning and students benefits. The History Teacher, 32(1), 49-76.

Nersater, A. (2019). Students understanding of historical sources- a composite ability. Journal of Humanities and Social Science Education, 1, 105-131.

Nokes, J.D. (2014). Elementary students' role and epistemic stances during document=based history lessons. Theory \& Research in Social Education, 42(3), 375-413.

Nunnally, J.C. (1978). Psychometrie Theory $\left(2^{\text {nd }}\right.$ ed). New York: McGraw Hill

Nusbaum, L (2014). The effects of narrative empathy on social and emotional behavior. Kentucky Reading Journal, 20-31.

Perrota, K. (2018). A study student's social identities and a "historical empathy gaps" in middle and secondary social studies classes with the in-structured unit "The Elizabeth Jennings Progelt". Curriculum and Teaching Dialogue, 20(1-2), 53-69.

Pusat Perkembangan Kurikulum. (2003). Huraian sukatan pelajaran tingkatan empat. Kuala Lumpur: Kementerian Pendidikan Malaysia.

Pusat Perkembangan Kurikulum. (2018). Dokumen Standard Kurikulum dan Pentaksiran Mata Pelajaran Sejarah Tingkatan Empat dan Lima. Putrajaya: Kementerian Pendidikan Malaysia.

Ramoroka, D \& Engelbrecht, A. (2018). The dialectics of historical empathy as a reflection of historical thinking in South African classroom. Yesterday \& Today, 20, 46-71.

Reisman, A. (2012). Reading like a historian: A document based history curriculum intervention in urban high schools. Cognition and Instruction, 30(1), 86-112.

Rohaimi Ishak \& Ramlah Jantan. (2015). Tinjauan persepsi pelajar terhadap mata pelajaran sejarah sekolah rendah. Asian Education Action Research Journal, 4, 64-80.

Rosfiani, O., Akhbar, M \& Neolaka, A. (2019). Assessing students' social studies learning: effects of learning environment, inquiry \& student learning interest. TARBIYA: Journal of Education on Mualim Society Website, 6(1), 45-56.

Rosy Talin. (2013). Students preferences in learning history. Global Advanced Research Journal of Arts and Humanities (GARJAH), 2(2), 14-19.

Rosy Talin. (2014). The teaching of history in secondary schools. International Journal of Social Sciences and Humanities Research, 2(3), 72-78.

Sandwell, R.M. (2008). Using primary documents in social studies and history. The Anthology of Social Studies: Issues and Strategies for secondary Teacher, 2, 295-307.

Sharifah Nor Puteh, Nooreiny Maarof, \& Elisabeth Tak (2010). Students' perceptions of the teaching of historical thinking skills. Pertanika ournals Social Science \& Humanities, 18(S), 87-95. 
Slekar, T.D (2009). Learning to teach history in elementary school. Social Studies Teacher Education: Dare we teach for democracy? 36(1), 95-116.

Stearns, P.N. (1998). Why study history? American Historical Association, 1-8.

Stewart, W, Iran-Nejad, A \& Robinson, C. (2008). Using learner insight to foster understanding in history education. Research in the Schools, 15(1), 38-50.

Stovel, J.E. (2000). Document analysis as a tool to strengthen student writing. The History Teacher, $33(4), 501-509$.

Swans, K.O., Hofer, M \& Gallicchio, L. (2006). Historical scene investigating (HIS): Engaging students in case based investigations using web based historical documents. Social Studies Research and Practice, 1(2), 250-261.

Tan, D.H. (2004). What is history teaching and Learning? Teaching and Learning, 25(2), 197-206.

Theresa, C \& Noonen (1999). Document based activities for global history classes. Western Walch Publisher: Pertland Mains.

Thorp, R \& Persson, A. (2020). On historical thinking and the history educational thinking and the history educational challenges. Educational Philosophy and Theory, 1-12.

Van Hover, S., Hicks, D \& Dack, H. (2016). From sources to evidens? Teachers' use of historical sources in their classrooms. The Social Studies, 107(6), 209-217.

Wineburg, S., Smith, M \& Breakstone, J. (2018). What is learned in college history classes? The Journal of American History, 983-993.

Woyshner, C. (2018). Inquiry teaching with primary source documents: an iterative approach. Social Studies Research and Practice, 5(3), 36-45. 